\title{
Physical Activity Motivation Climate Questionnaire: Validity, Reliability and Measurement Invariance
}

\author{
Tao Zhong ${ }^{1^{*}}$, Hui Wang ${ }^{2}$ \\ ${ }^{1}$ College of Sport and Health, Henan Normal University, Xinxiang, China \\ ${ }^{2}$ College of Sport and Health, Zhejiang Sci-Tech University, Hangzhou, China
}

*Corresponding Author: Dr. Tao Zhong, Researcher, College of Sport and Health, Henan Normal University, Xinxiang, China

\begin{abstract}
:
Objective: A physical activity motivation climate, characterized by autonomy support, is important for physical activity participation and adherence. The research aimed to examine the validity, reliability, and measurement invariance of the Physical Activity Motivation Climate Questionnaire (PAMCQ) for autonomysupport perception measurement.
\end{abstract}

Methods: A sample of 407 Chinese completed a questionnaire package. The PAMCQ's validity (factorial validity and nomological validity), reliability (internal consistency and composite reliability), and measurement invariance across gender and age, were subsequently tested.

Results: Confirmatory factor analysis (CFA) supported the factorial validity of the scale. Its nomological validity was corroborated by its association with conceptually linked construct. The Cronbach's alpha coefficient and composite reliability score indicated sufficient reliability of the PAMCQ. Measurement invariance of the scale was also found across gender and age through multi-group CFA.

Conclusion: Overall, findings from the present research suggest the PAMCQ holds adequate psychometric properties to measure perception of an autonomy-supportive motivation climate in the physical activity context. It can be used in future pertinent research as a valid and reliable tool.

Keywords: Physical Activity, Motivation Climate, Autonomy Support, Self-Determination Theory, Measurement Assessment

\section{INTRODUCTION}

Regular physical activity is a key facilitator of health[1]. However, in spite of the well documented evidence concerning its physical and mental health benefits, a significant number of people fail to maintain an active lifestyle[2]. As such, how to promote physical activity is an urgent issue to be addressed. Among factors that can influence people's physical activity behavior, motivation is of importance[3]. Self-determination theory (SDT), as a prominent motivation theory[4,5], may contribute to our understanding of physical activity behavior.

SDT underscores the importance of fostering an autonomy-supportive motivation climate. Such climate is characterized by minimizing control, providing choice to autonomous decision making process, supporting individuals' initiative, eliciting and considering individuals' viewpoint[6].It is suggested that an autonomy-supportive motivation climate is contributive to the internalization of behavioral regulation, which can have a positive influence on adaptive behavior outcomes, such as physical activity behavior[7-9].Such internalization denotes the process in which less self-determined behavioral regulations are transformed to more self-determined behavioral regulations along a continuum. From the least to the most self-determined form, they are a motivation, external regulation, introjected regulation, identified regulation, integrated regulation, and intrinsic motivation[10].

Given the importance of an autonomy-supportive motivation climate in the physical activity context, a valid and reliable instrument is desirable. Past research has widely adapted the 6-item short form of the Health Care Climate Questionnaire (HCCQ) for use[7,11]. However, the HCCQ is designed initially for measuring patients' perception of the extent to which health care professionals provide 
autonomy support[12], and the psychometric evidence of the scale in the physical activity context is lacking. Therefore, the aim was to examine the psychometric properties (validity, reliability and measurement invariance) of the physical activity adapted HCCQ, named PAMCQ in the current study.

\section{Methods \& MATERials}

\subsection{Participants and Procedure}

Participants in this study were recruited through convenience sampling in Hong Kong. In total, 407 participants started and completed an online survey. The mean age of the participants was $40.59 \pm$ 13.76, age range 18-63, with 188 males and 219 females.

Prior to undertaking the research, ethical clearance from a local university research ethics committee was received. Invitation pamphlets, containing the study's information and a QR code of the online survey, were created and distributed to university students in Hong Kong, to invite them and people aged 18-64 in their close environment (i.e., relatives and friends) to participate in the study. Informed consent was obtained from the participants.

\subsection{Measurements}

\subsubsection{Motivation Climate}

Perception of autonomy-supportive motivation climate in the physical activity context was measured with the PAMCQ. It was developed by adapting the short-form of the HCCQ to account for the characteristics of physical activity context. Specifically, reference "physician" was replaced with "important others", which include people such as physical activity instructors, family members and friends who may exert an impact on physical activity engagement. Also, item 3 "make changes" was substituted with "make decisions", and item 6 "suggesting a new way to do things" was changed to "offering a suggestion". A translation and back-translation procedure was followed to translate the English version of the PAMCQ into Chinese[13,14]. Following this, a cognitive test was performed among ten Chinese adults (age $=40.90 \pm 15.35$, age range 18-64, five males and five females) in Hong Kong. According to their feedback, the content of the scale was comprehensible, and no further adjustment was suggested to made. Thus, the PAMCQ was finalized for subsequent administration. It consists of 6 items, and a seven-point Likert scale is used to anchor responses, ranging from 1(strongly disagree) to 7(strongly agree). Scoring is by averaging scores on individual items. A higher score represents a higher level of perceived autonomy support in the context of physical activity.

\subsubsection{Behavioral Regulation}

It was assessed with the Chinese version of the Behavioral Regulations in Exercise Questionnaire - 2 (BREQ-2)[15], which was translated from the English version[16]. It was used for the nomological validity evaluation of the PAMCQ. Eighteen items are included in the instrument, with four items in the amotivation subscale, four items in the external regulation subscale, three items in the introjected regulation subscale, three items in the identified regulation subscale and four items in the intrinsic motivation subscale. Five-point Likert scale is used to determine to what extent a particular item suits participants (from 1 = "not true for me" to " 5 = very true for me"). The reliability and validity of the questionnaire have been demonstrated [15]. Slight modification was made to adapt the BREQ-2 to the PA context. Specifically, the term "exercise" was replaced with "physical activity" for all the RAI. RAI, the widely adopted index to reflect self-determined behavioral regulation in prior research $[17,18]$, was used. The following formula, based on the extent of self-determination of individual behavioral regulations, was employed for its calculation: RAI $=$ Amotivation * $(-3)+$ External regulation $*(-2)+$ introjected regulation $*(-1)+$ identified regulation $*(2)+$ intrinsic motivation $*$ (3). A higher score of RAI reflects a higher degree of self-determination in behavioral regulation for physical activity[19,20].

\subsection{Data Analysis}

First, confirmatory factor analysis (CFA) was introduced to test the factorial validity of the PAMCQ via the software Mplus version 6.0. Robust maximum likelihood estimation was used which can withstand potential violation of the normality assumption of the data. As for the judgment of goodness-of-fit of the model to the data, multiple model fit indices, including comparative fit index (CFI), Tucker-Lewis index (TLI), root mean square error of approximation (RMSEA) accompanied with its $90 \%$ confidence interval ( $90 \% \mathrm{CI}$ ), and standardized root mean square residual (SRMR), were 
used[21,22]. Cut-off values of 0.90 and 0.95 for CFI and TLI, and cut-off values of 0.08 and 0.06 for RMSEA and SRMR, were used to represent acceptable and good fit, respectively [21,22].

Second, once the factorial validity of the PAMCQ was confirmed, nomological validity evaluation of the scale, through correlation analysis with related SDT construct, was conducted. It was hypothesized that perceived autonomy support would be positively associated with self-determined behavioral regulation[23].

Third, the reliability of the PAMCQ was investigated via Cronbach's alpha coefficient [24,25], and composite reliability score[26]. Scores of Cronbach's alpha coefficient and composite reliability larger than .70 and .80 were employed in the study to represent acceptable and good reliability, respectively $[27,28]$.

Fourth, multi-group CFA was implemented to examine whether disparate groups across gender and age would interpret the scale in the same vein. Gradually constrained invariance tests including configural, metric and scalar invariance were tested. Since error variance invariance is of little interest and considered unnecessary, it was not examined. When it comes to the criteria for measurement invariance, change of CFI and RMSEA less than .010 and .015 respectively was introduced for determining measurement invariance[29].

\section{RESUltS}

CFA revealed an adequate goodness-of-fit of the model to the data, where $\chi^{2}(9)=26.449, p<.01$, CFI $=.980, \mathrm{TLI}=.966$, RMSEA $(90 \% \mathrm{CI})=.069(.039, .100)$, SRMR $=.027$. Standardized factor loadings were all above .700, with $p<.001$. Therefore, the scale's factorial validity was established. Item mean value, standard deviation, skewness, kurtosis, and standardized factor loading are displayed in Table 1.

Table1. Item content, descriptive analysis and standardized factor loading $(N=407)$

\begin{tabular}{|l|c|c|c|c|c|}
\hline \multicolumn{1}{|c|}{ Item Content } & Mean & SD & SK & KU & FL \\
\hline $\begin{array}{l}\text { 1. I feel that my important others have provided me with choices and } \\
\text { options in physical activity. }\end{array}$ & 4.811 & 1.275 & -.329 & -.313 & .741 \\
\hline 2. I feel understood by my important others in physical activity. & 4.914 & 1.164 & -.256 & -.172 & .714 \\
\hline $\begin{array}{l}\text { 3. My important others convey confidence in my ability to make decisions } \\
\text { in physical activity. }\end{array}$ & 4.835 & 1.191 & .014 & -.450 & .706 \\
\hline 4. My important others encourage me to ask questions in physical activity. & 4.740 & 1.354 & -.159 & -.594 & .837 \\
\hline $\begin{array}{l}\text { 5. My important others listen to how I would like to do things in physical } \\
\text { activity. }\end{array}$ & 4.764 & 1.318 & -.324 & -.206 & .816 \\
\hline $\begin{array}{l}\text { 6. My important others try to understand how I see physical activity } \\
\text { before offering a suggestion. }\end{array}$ & 4.607 & 1.364 & -.112 & -.551 & .779 \\
\hline
\end{tabular}

Note: SD, Standard deviation; SK, Skewness; KU, Kurtosis. FL, Standardized factor loading

With regard to the scale's nomological validity, perceived autonomy support was positively correlated with RAI $(\mathrm{r}=.220, \mathrm{p}<.001)$, the index which reflects to what extent an individual's behavioral regulation is self-determined. As to the appraisal of the PAMCQ's reliability, the values of Cronbach's alpha coefficient and composite reliability score were .896 and .896 , respectively, indicating good reliability of the scale.

Table2. Measurement Invariance across Gender and Age $(N=407)$

\begin{tabular}{|c|c|c|c|c|c|c|c|c|c|c|}
\hline Model & $\begin{array}{c}\text { Model } \\
\text { comparison }\end{array}$ & $\chi^{2}$ & $d f$ & $p$ & CFI & $\Delta \mathrm{CFI}$ & TLI & $\begin{array}{l}\text { RMSEA } \\
(90 \% \text { CI })\end{array}$ & \begin{tabular}{|c|}
$\Delta \mathrm{RMSE}$ \\
$\mathrm{A}$
\end{tabular} & SRMR \\
\hline \multicolumn{11}{|l|}{ Gender invariance } \\
\hline Male $(\mathrm{N}=178)$ & -- & 13.778 & 9 & .131 & .988 & - & .981 & $.055(.000, .109)$ & -- & .026 \\
\hline Female $(\mathrm{N}=229)$ & -- & 21.713 & 9 & .001 & .972 & - & .954 & $.079(.036, .121)$ & -- & .034 \\
\hline M1 & -- & 35.414 & 18 & .001 & .980 & - & .967 & $.069(.034-.102)$ & -- & .031 \\
\hline M2 & M1 vs M2 & 45.978 & 23 & .003 & .974 & .006 & .966 & $.070(.040-.099)$ & .001 & .065 \\
\hline M3 & M2 vs M3 & 59.174 & 29 & .001 & .965 & .009 & .964 & $.072(.045-.098)$ & .002 & .069 \\
\hline \multicolumn{11}{|l|}{ Age invariance } \\
\hline Young $(\mathrm{N}=209)$ & -- & 14.488 & 9 & .106 & .986 & -- & .977 & $.054(.000-.103)$ & -- & .029 \\
\hline Old $(\mathrm{N}=198)$ & -- & 20.046 & 9 & .018 & .977 & -- & .962 & $.079(.031-.125)$ & -- & .030 \\
\hline
\end{tabular}




\begin{tabular}{|l|l|l|l|l|l|l|l|l|l|l|}
\hline M1 & -- & 35.648 & 18 & .008 & .980 & -- & .966 & $.069(.035-.103)$ & -- & .030 \\
\hline M2 & M1 vs M2 & 40.493 & 23 & .014 & .980 & .000 & .974 & $.061(.028-.092)$ & .008 & .038 \\
\hline M3 & M2 vs M3 & 53.774 & 29 & .003 & .971 & .009 & .970 & $.065(.037-.091)$ & .004 & .055 \\
\hline
\end{tabular}

Note: Median age (46.00) of the participants was used for age group division (G1 and G2); M1, configural invariance; M2, metric invariance; $\mathrm{M} 3$, scalar invariance

The result of multi-group invariance test is presented in Table 2. Based on goodness-of-fit indices, both the independent models and invariance models showed a sufficient fit to the data. When comparing the models constrained to varying degrees, changes in model fit indices (i.e. CFI and RMSEA) were all smaller than suggested cut-off values indicative of measurement invariance. The result supported the scale was invariant across gender and age groups, which suggested that participants from different sub-group interpreted the PAMCQ in the same manner.

\section{DISCUSSION}

A motivation climate characterized by autonomy support can foster the internalization of selfdetermined behavioral regulation[23], which in turn can contribute to adaptive behavioral outcomes such as physical activity behavior[7,30,31]. To investigate such motivation climate rigorously in empirical research, its measurement must be valid and reliable. However, even though the HCCQ has been widely used in the physical activity context for perceived autonomy support measurement, the soundness of the adapted instrument in the specific context remains unclear. Therefore, he objective of the study was to examine the psychometric soundness of the PAMCQ.

The CFA supported the factorial validity of the PAMCQ in the present study, with an adequate fit of the constructed model to the data, and standardized factor loadings of all the items larger than .700 . Also, the PAMCQ's nomological validity was examined and established. Specifically, it was found perceived autonomy support was positively associated with RAI, which is in line with past findings[23]. This indicates that individuals who perceived a higher autonomy support were more likely to be self-determined in their behavioral regulation for physical activity participation. With regard to the reliability of the scale, the Cronbach's alpha coefficient and composite reliability score substantiated the reliability of the scale, with values higher than the cut-off point .80 as indicative of good reliability[27,28].

Furthermore, the measurement invariance test was performed across gender and age groups. Measurement invariance test is a key indicator of psychometric property of a measurement[32], and it is considered necessary to encompass such a test for the PAMCQ. Measurement invariance tests whether a given scale is interpreted in a conceptually similar fashion across different groups with different background. Its violations may diminish meaningful interpretation of a measurement[33]. The analysis result in the current research showed that the PAMCQ displayed sufficient measurement equivalence property via comparisons between male and female participants, and between age groups. Thus, it is concluded that the PAMCQ is interpreted by different groups in the same way, which adds additional merit to the scale.

Though the study has corroborated the utility of the scale in the physical activity setting, limitations and future directions should also be acknowledged. For instance, apart from Cronbach's alpha coefficient and composite reliability, the scale's temporal stability is also suggested to be examined, in order to provide more reliability information. Also, sensitivity of the scale should be of interest in future study.

\section{CONCLUSION}

This study is the first to empirically examine the psychometric properties of the PAMCQ. It provides promising evidence of the validity, reliability and measurement invariance of the scale. Even though scale validation is an on-going process, it is believed that the PAMCQ can be a useful tool for proliferating relevant research in understanding and predicting physical activity behavior, from a motivation climate approach.

\section{REFERENCES}

[1] Pratt, M.; Norris, J.; Lobelo, F.; Roux, L.; Wang, G. The cost of physical inactivity: moving into the $21 \mathrm{st}$ century. Br. J. Sports Med.2014, 48, 171-173.

[2] Kangasniemi, A.M.; Lappalainen, R.; Kankaanpää, A.; Tolvanen, A.; Tammelin, T. Towards a physically more active lifestyle based on one's own values: the results of a randomized controlled trial among physically inactive adults. BMC Public Health 2015, 15, 1-14. 
[3] Bauman, A.E.; Reis, R.S.; Sallis, J.F.; Wells, J.C.; Loos, R.J.F.; Martin, B.W. Correlates of physical activity: why are some people physically active and others not? Lancet 2012, 380, 258-271.

[4] Deci, E.L.; Ryan, R.M. Self-determination theory: A macrotheory of human motivation, development, and health. Can. Psychol. Can.2008, 49, 182-185.

[5] Deci, E.L.; Ryan, R.M. The" what" and" why" of goal pursuits: Human needs and the self-determination of behavior. Psychol. Inq.2000, 11, 227-268.

[6] Ryan, R.M.; Deci, E.L. Self-determination theory and the facilitation of intrinsic motivation, social development, and well-being. Am. Psychol.2000, 55, 68-78.

[7] Edmunds, J.; Ntoumanis, N.; Duda, J.L. A test of self-determination theory in the exercise domain. J. Appl. Soc. Psychol.2006, 36, 2240-2265.

[8] Silva, M.N.; Markland, D.; Vieira, P.N.; Coutinho, S.R.; Carraça, E. V; Palmeira, A.L.; Minderico, C.S.; Matos, M.G.; Sardinha, L.B.; Teixeira, P.J. Helping overweight women become more active: need support and motivational regulations for different forms of physical activity. Psychol. Sport Exerc.2010, 11, 591-601.

[9] Thøgersen-Ntoumani, C.; Ntoumanis, N. The role of self-determined motivation in the understanding of exercise-related behaviours, cognitions and physical self-evaluations. J. Sports Sci.2006, 24, 393-404.

[10] Ryan, R.M.; Deci, E.L. On happiness and human potentials: A review of research on hedonic and eudaimonic well-being. Annu. Rev. Psychol.2001, 52, 141-166.

[11] Wilson, P.M.; Rodgers, W.M. The relationship between perceived autonomy support, exercise regulations and behavioral intentions in women. Psychol. Sport Exerc.2004, 5, 229-242.

[12] Williams, G.C.; Grow, V.M.; Freedman, Z.R.; Ryan, R.M.; Deci, E.L. Motivational predictors of weight loss and weight-loss maintenance. J. Pers. Soc. Psychol.1996, 70, 115-26.

[13] Brislin, R.W. Back-translation for cross-cultural research. J. Cross. Cult. Psychol.1970, 1, 185-216.

[14] Beaton, D.E.; Bombardier, C.; Guillemin, F.; Ferraz, M.B. Guidelines for the process of cross-cultural adaptation of self-report measures. Spine 2000, 25, 3186-3191.

[15] Chung, P.K.; Liu, J.D. Examination of the psychometric properties of the Chinese translated behavioral regulation in exercise questionnaire-2. Meas. Phys. Educ. Exerc. Sci.2012, 16, 300-315.

[16] Markland, D.; Tobin, V. A modification to the behavioural regulation in exercise questionnaire to include an assessment of amotivation. J. Sport Exerc. Psychol.2004, 26, 191-196.

[17] Solberg, P.A.; Halvari, H.; Ommundsen, Y. Linking exercise and causality orientations to change in well-being among older adults: does change in motivational variables play a role? J. Appl. Soc. Psychol. 2013, 43, 1259-1272.

[18] Verloigne, M.; De Bourdeaudhuij, I.; Tanghe, A.; D’Hondt, E.; Theuwis, L.; Vansteenkiste, M.; Deforche, B. Self-determined motivation towards physical activity in adolescents treated for obesity: an observational study. Int. J. Behav. Nutr. Phys. Act.2011, 8, 1-11.

[19] Silva, M.N.; Sánchez-Oliva, D.; Brunet, J.; Williams, G.C.; Teixeira, P.J.; Palmeira, A.L. "What Goes Around Comes Around": Antecedents, Mediators, and Consequences of Controlling vs. Need-Supportive Motivational Strategies Used by Exercise Professionals. Ann. Behav. Med.2017, 51, 707-717.

[20] Wilson, P.M.; Sabiston, C.M.; Mack, D.E.; Blanchard, C.M. On the nature and function of scoring protocols used in exercise motivation research: An empirical study of the behavioral regulation in exercise questionnaire. Psychol. Sport Exerc.2012, 13, 614-622.

[21] Hu, L.; Bentler, P.M. Cutoff criteria for fit indexes in covariance structure analysis: Conventional criteria versus new alternatives. Struct. Equ. Model. a Multidiscip. J.1999, 6, 1-55.

[22] Marsh, H.W.; Hau, K.-T.; Wen, Z. In search of golden rules: Comment on hypothesis-testing approaches to setting cutoff values for fit indexes and dangers in overgeneralizing $\mathrm{Hu}$ and Bentler's (1999) findings. Struct. Equ. Model.2004, 11, 320-341.

[23] Hagger, M.S.; Chatzisarantis, N.L.D.; Barkoukis, V.; Wang, C.K.; Baranowski, J. Perceived autonomy support in physical education and leisure-time physical activity: a cross-cultural evaluation of the transcontextual model. J. Educ. Psychol.2005, 97, 376-390.

[24] Cronbach, L.J. Coefficient alpha and the internal structure of tests. Psychometrika1951, 16, $297-334$.

[25] Santos, J.R.A. Cronbach's alpha: A tool for assessing the reliability of scales. J. Ext.1999, 37, 1-5.

[26] Bacon, D.R.; Sauer, P.L.; Young, M. Composite reliability in structural equations modeling. Educ. Psychol. Meas.1995, 55, 394-406.

[27] Nunnally, J.C.; Bernstein, I.H. Psychometric Theory (McGraw-Hill Series in Psychology) (Vol. 3). New York: McGraw-Hill, 1994.

[28] De Smedt, D.; Clays, E.; Doyle, F.; Kotseva, K.; Prugger, C.; Pająk, A.; Jennings, C.; Wood, D.; De Bacquer, D.; Group, E.S. Validity and reliability of three commonly used quality of life measures in a large European population of coronary heart disease patients. Int. J. Cardiol.2013, 167, 2294-2299. 
[29] Byrne, B.M. Structural equation modeling with Mplus: Basic concepts, applications, and programming Routledge, 2013

[30] Weman-Josefsson, K.; Lindwall, M.; Ivarsson, A. Need satisfaction, motivational regulations and exercise: moderation and mediation effects. Int. J. Behav. Nutr. Phys. Act.2015, 12, 1-11.

[31] Edmunds, J.; Ntoumanis, N.; Duda, J.L. Adherence and well-being in overweight and obese patients referred to an exercise on prescription scheme: A self-determination theory perspective. Psychol. Sport Exerc.2007, 8, 722-740.

[32] Vandenberg, R.J.; Lance, C.E. A review and synthesis of the measurement invariance literature: Suggestions, practices, and recommendations for organizational research. Organ. Res. methods2000, 3, 470.

[33] Milfont, T.L.; Fischer, R. Testing measurement invariance across groups: Applications in crosscultural research. Int. J. Psychol. Res.2010, 3, 111-121.

Citation: Tao Zhong, Hui Wang. "Physical Activity Motivation Climate Questionnaire: Validity, Reliability and Measurement Invariance "International Journal of Sports and Physical Education (IJSPE), vol 5, no.1, 2019, pp. 13-18. doi: http://dx.doi.org/ 10.20431/2454-6380.0501003.

Copyright: (C) 2019 Authors. This is an open-access article distributed under the terms of the Creative Commons Attribution License, which permits unrestricted use, distribution, and reproduction in any medium, provided the original author and source are credited. 